\title{
Encephalopathies Associated With Severe COVID-19 Present Neurovascular Unit Alterations Without Evidence for Strong Neuroinflammation
}

\author{
Raphael Bernard-Valnet, MD, PhD, * Sylvain Perriot, PharmD, PhD, * Mathieu Canales, MSc, \\ Beatrice Pizzarotti, MD, Leonardo Caranzano, MD, Mayté Castro-Jiménez, MD, Jean-Benoit Epiney, MD, \\ Sergiu Vijiala, MD, Paolo Salvioni-Chiabotti, MD, MSc, Angelica Anichini, MD, Alexander Salerno, MD, \\ Katia Jaton, MD, PhD, Julien Vaucher, MD, Matthieu Perreau, PhD, Gilbert Greub, MD, PhD, \\ Giuseppe Pantaleo, MD, and Renaud A. Du Pasquier, MD
}

Neurol Neuroimmunol Neuroinflamm 2021;8:e1029. doi:10.1212/NXI.0000000000001029

\section{Abstract \\ Objective}

Coronavirus disease (COVID-19) has been associated with a large variety of neurologic disorders. However, the mechanisms underlying these neurologic complications remain elusive. In this study, we aimed at determining whether neurologic symptoms were caused by severe acute respiratory syndrome coronavirus 2 (SARS-CoV-2) direct infection or by either systemic or local proinflammatory mediators.

\section{Methods}

In this cross-sectional study, we checked for SARS-CoV-2 RNA by quantitative reverse transcription PCR, SARS-CoV-2-specific antibodies, and 49 cytokines/chemokines/growth factors (by Luminex) in the CSF +/- sera of a cohort of 22 COVID-19 patients with neurologic presentation and 55 neurologic control patients (inflammatory neurologic disorder [IND], noninflammatory neurologic disorder, and MS).

\section{Results}

We detected anti-SARS-CoV-2 immunoglobulin G in patients with severe COVID-19 with signs of intrathecal synthesis for some of them. Of the 4 categories of tested patients, the CSF of IND exhibited the highest level of cytokines, chemokines, and growth factors. By contrast, patients with COVID-19 did not present overall upregulation of inflammatory mediators in the CSF. However, patients with severe COVID-19 (intensive care unit patients) exhibited higher concentrations of CCL2, CXCL8, and vascular endothelium growth factor A (VEGF-A) in the CSF than patients with a milder form of COVID-19. In addition, we could show that intrathecal CXCL8 synthesis was linked to an elevated albumin ratio and correlated with the increase of peripheral inflammation (serum hepatocyte growth factor [HGF] and CXCL10).

\section{Conclusions}

Our results do not indicate active replication of SARS-CoV-2 in the CSF or signs of massive inflammation in the CSF compartment but highlight a specific impairment of the neurovascular unit linked to intrathecal production of CXCL8.

\author{
Correspondence \\ Dr. Bernard-Valnet \\ raphael.bernard-valnet@chuv.ch
}




\section{Glossary}

COVID-19 = coronavirus disease 2019; BBB = blood-brain barrier; HGF = hepatocyte growth factor; IFN = interferon; IgG = immunoglobulin G; IL = interleukin; IND = inflammatory neurologic disorder; $\mathbf{M F I}=$ mean fluorescent intensity; $\mathbf{m R N A}=$ messenger RNA; NIND = noninflammatory neurologic disorder; RT-qPCR = quantitative reverse transcription PCR; SAE = sepsisassociated encephalopathy; SARS-CoV-2 = severe acute respiratory syndrome coronavirus 2 ; TNF = tumor necrosis factor.

Coronaviruses' outbreaks have been repeatedly associated with neurologic disorders. Indeed, human tropic coronaviruses seem able to reach the CNS and are found in brain necropsies and in the CSF of patients with severe acute respiratory syndrome coronavirus (SARS-CoV). ${ }^{1,2}$

Coronavirus disease 2019 (COVID-19) has shown a large range of neurologic complications ${ }^{3}$ that may be classified as follows: critical care-related neurologic syndromes either central (encephalopathy with subcortical deficit characterized by attention and executive dysfunction) or peripheral (critical care-associated polyneuropathies or myopathies), ${ }^{4}$ anosmia/ dysgeusia, ${ }^{5}$ myelomeningoencephalitis, ${ }^{6}$ Guillain-Barré syndrome and its variant affecting cranial nerves (Miller-Fisher syndrome), ${ }^{7}$ and cerebrovascular disease (strokes). ${ }^{8}$

If data from previous outbreaks point to a neurotropism of the coronaviruses, the pathophysiology underlying SARS-CoV2-related neurologic deficits remains elusive. Indeed, data showing direct invasion of the CNS by SARS-CoV-2 remain scarce as messenger RNA (mRNA) of SARS-CoV-2 is rarely found in the CSF and autopsies do not show widespread infection of the brain. ${ }^{9,10}$ Furthermore, pathology did not find evidences of extensive neuronal loss associated with the presence of the virus. Thus, the main hypotheses to explain neurologic complications in patients with COVID point at mechanisms related to low-grade presence of the virus in the CNS, to disturbance of the blood-brain interface by the action of peripheral cytokines on the brain endothelium, or to the presence of an autoimmune response, such as antineuronal antibodies by analogy to what occurs in autoimmune encephalitis. ${ }^{11}$ However, data firmly establishing one or the other hypothesis are still missing. Yet, the fact that encephalitis/encephalopathies caused by SARS-CoV-2 may respond to corticosteroids ${ }^{12,13}$ suggests the involvement of immune mechanisms.

In an attempt to decipher mechanisms underlying neurologic symptoms, we looked at SARS-CoV-2-encoding RNA, SARS-CoV-2-specific antibodies, and a panel of 49 cytokines/chemokines/growth factors in the CSF of 77 study patients. Twenty-two of them suffered from COVID-19, and 55 were control SARS-CoV-2-negative patients suffering from inflammatory neurologic disorder (IND), including MS, or noninflammatory neurologic disorder (NIND). We found that patients with COVID-19 hospitalized in the intensive care unit (ICU) present signs of blood-brain barrier (BBB) impairment linked to possible astrocyte/glial activation but no strong immune response in the CSF or obvious CNS infection by the virus.

\section{Methods}

\section{Study Population}

In this cross-sectional study, all consecutive patients seen at the Lausanne University Hospital during the ongoing COVID-19 pandemic (March to the end of December 2020) with any neurologic manifestations and for whom a lumbar puncture including SARS-CoV-2 PCR on the CSF was performed were included in this study. Patients with a nasopharyngeal swab positive for SARS-CoV-2 detection by reverse transcription (RT)-PCR and/or a serology test for anti-SARS-CoV-2 antibodies together with clinical presentation of SARS-CoV-2 infection were defined as patients with COVID-19 (25 patients). Of those 25 patients, 3 have a neurologic presentation that was likely explained by another condition than COVID-19. Therefore, they were removed from the study. The 22 enrolled patients with COVID-19 were further divided into 2 subgroups whether they requested the ICU, hereafter referred to as severe COVID19 (13 patients), or not, hereafter referred to as moderate COVID-19 (9 patients). Patients whose nasopharyngeal swab RT-PCR test came back negative were enrolled as controls and classified as IND (9 patients) or NIND (4 patients) depending on their diagnosis. The control cohort also included 42 patients who were diagnosed with IND (12 patients), NIND (15 patients), or MS (15 patients). Serum and CSF of these 42 patients had been drawn before the COVID-19 pandemic, in the frame of the COOLIN'BRAIN cohort, between 2009 and 2019. In the subsequent analyses, patients with IND who were enrolled during the pandemic period were pooled with the patients with IND enrolled before 2020, through COOLIN'BRAIN. The same is true for NIND. Detailed diagnosis for NIND and IND is reported in table e-1 (links.lww.com/NXI/A499). Samples (serum and CSF) from patients with MS were all obtained during a clinical relapse of MS before any corticosteroid treatment.

\section{EEG}

Routine EEG was performed with portable EEG machines using 21 electrodes arranged after the international 10-20 system and interpreted by certified reviewers.

\section{Samples}

In all study patients, the lumbar puncture was performed at the acute phase of neurologic symptoms. When available, we also analyzed serum collected at the same time as the CSF to obtain paired samples (16/22 patients with COVID-19, 14/21 patients 
Table 1 Detailed Clinical and Paraclinical Characteristics of SARS-CoV-2-Infected Patients

\begin{tabular}{|c|c|c|c|}
\hline & Moderate SARS-CoV-2 $(n=9)$ & Severe SARS-CoV-2 $(n=13)$ & $p$ Value \\
\hline \multicolumn{4}{|l|}{ Demographic data } \\
\hline Age, mean [range] & 48.1 [19-69] & $69.1[53-90]$ & 0.0059 \\
\hline Sex, male/female & $4 / 5$ & $8 / 5$ & 0.67 \\
\hline BMI, mean [range] & 26.8 [19-37] & 30 [19.5-45] & 0.57 \\
\hline \multicolumn{4}{|l|}{ SARS-CoV-2 mRNA } \\
\hline Nasal swab, n (\%) & $8(89)$ & $12(92)$ & - \\
\hline CSF, n (\%) & $0(0)$ & $0(0)$ & - \\
\hline \multicolumn{4}{|l|}{ Preexisting comorbidities, n (\%) } \\
\hline Neurodegenerative disease & $0(0)$ & $4(31)$ & 0.11 \\
\hline Stroke & $2(20)$ & $1(7.7)$ & 0.54 \\
\hline Immunosuppressive condition/HIV & $0(0)$ & $0(0)$ & - \\
\hline Malignancy & $0(0)$ & $2(15)$ & 0.50 \\
\hline \multicolumn{4}{|l|}{ COVID-19 evolution } \\
\hline Delay between first symptoms and admission, $d$, mean [range] & $5.7[0-21]$ & $6.9[0-15]$ & 0.34 \\
\hline ICU admission, $\mathbf{n}(\%)$ & $0(0)$ & $13(100)$ & - \\
\hline Mechanical ventilation, $\mathbf{n}(\%)$ & $0(0)$ & $9(69)$ & 0.0017 \\
\hline Pulmonary embolism, n (\%) & $0(0)$ & $1(7.7)$ & $>0.99$ \\
\hline \multicolumn{4}{|l|}{ COVID-19-specific treatments, n (\%) } \\
\hline Any treatment & $2(22)$ & $11(84)$ & 0.007 \\
\hline Lopinavir & $0(0)$ & $4(30)$ & 0.11 \\
\hline Tocilizumab & $0(0)$ & $1(7.7)$ & $>0.99$ \\
\hline Hydroxychloroquine & $0(0)$ & $5(38.5)$ & 0.054 \\
\hline Corticosteroids & $2(22)$ & $5(38.5)$ & 0.65 \\
\hline \multicolumn{4}{|l|}{ Neurologic characteristics of SARS-CoV-2 infection } \\
\hline \multicolumn{4}{|l|}{ Main neurologic diagnosis, $\mathbf{n}(\%)$} \\
\hline Headache/vertigo & $4(44)$ & $0(0)$ & 0.017 \\
\hline Encephalitis/meningitis/myelitis & $2(22)$ & $1(7.7)$ & 0.54 \\
\hline Encephalopathy & $1(11)$ & $11(85)$ & 0.0015 \\
\hline Acute peripheral neuropathy & $1(11)$ & $1(7.7)$ & $>0.99$ \\
\hline Optic neuropathy & $1(11)$ & $0(0)$ & 0.41 \\
\hline \multicolumn{4}{|l|}{ Delay, d, mean [range] } \\
\hline Between the onset of neurologic symptoms and LP & $3.3[0-16]$ & $6.8[0-21]$ & 0.36 \\
\hline Between admission and LP & 4 [0-29] & $22.2[0-49]$ & 0.038 \\
\hline \multicolumn{4}{|l|}{ Modified Rankin Scale, median [range] } \\
\hline Before infection & 0 [0-2] & $0[0-3]$ & 0.13 \\
\hline At discharge & $1[0-2]$ & $3[2-6]$ & $<0.0001$ \\
\hline Brain MRI, $\mathrm{n}$ performed & 10 & 10 & \\
\hline Diffusion restriction, $\mathrm{n}(\%)$ & $0(0)$ & $1(10)$ & $>0.99$ \\
\hline
\end{tabular}


Table 1 Detailed Clinical and Paraclinical Characteristics of SARS-CoV-2-Infected Patients (continued)

\begin{tabular}{|c|c|c|c|}
\hline & Moderate SARS-CoV-2 $(n=9)$ & Severe SARS-CoV-2 $(n=13)$ & $p$ Value \\
\hline Leptomeningeal/parenchymal gadolinium enhancement, $\mathbf{n}(\%)$ & $0(0)$ & $1(10)$ & $>0.99$ \\
\hline Microbleeds, n (\%) & $0(0)$ & $1(10)$ & $>0.99$ \\
\hline EEG, $n$ performed & 2 & 11 & \\
\hline Encephalopathy, $\mathrm{n}(\%)$ & $1(100)$ & $7(87.5)$ & - \\
\hline Irritative, $\mathbf{n}(\%)$ & $1(100)$ & $0(0)$ & - \\
\hline Nerve conduction study, $\mathrm{n}$ performed & 1 & 8 & \\
\hline Myopathy, n (\%) & $0(0)$ & $1(12.5)$ & - \\
\hline Polyneuropathy, n (\%) & $0(0)$ & $6(75)$ & - \\
\hline Mononeuritis multiplex, $\mathbf{n}(\%)$ & $1(100)$ & $0(0)$ & - \\
\hline Polyradiculopathy, n (\%) & $0(0)$ & $1(12.5)$ & - \\
\hline Neuropsychological, n performed & 0 & 5 & \\
\hline FAB, median [range] & - & $7[1-13]$ & - \\
\hline MoCA, median [range] & - & $15.25[4-26]$ & - \\
\hline
\end{tabular}

Abbreviations: $\mathrm{BMI}=$ body mass index; COVID-19 = coronavirus disease 2019; FAB = frontal assessment battery; ICU = intensive care unit; $\mathrm{LP}=$ lumbar puncture; MoCA = Montréal Cognitive Assessment; SARS-CoV-2 = severe acute respiratory syndrome coronavirus 2.

A Mann-Whitney test was used for the analysis of continuous variables and the Fisher exact test for categorical ones.

with IND, 15/19 patients with NIND, and 15/15 patients with MS). Samples of patients with COVID-19 and control patients were run at the same time for the detection of SARS-CoV-2 antibodies and cytokines/chemokines/growth factors.

\section{SARS-CoV-2 PCR}

SARS-CoV-2 tests in CSF specimens were performed using our automated platform with an in-house quantitative reverse transcription PCR (RT-qPCR) targeting the E-gene with the primers and probe described by Corman et al. ${ }^{14}$ SARS-CoV-2 tests in respiratory specimens were performed either using our automated platform (at the beginning of the pandemic) or using the cobas SARS-CoV-2 test on the cobas 6800 instrument (Roche, Basel, Switzerland), since March 24, 2020. Both methods were compared and exhibited $99.2 \%$ of concordant results. ${ }^{15}$

\section{SARS-CoV-2 Serology}

Anti-SARS-CoV-2 immunoglobulin G (IgG) specific to the native trimeric spike $(S)$ protein was quantified using a multiplex bead assay as previously described. ${ }^{16}$ Anti-SARS-CoV$2 \mathrm{IgG}$ levels were expressed as a ratio of the mean fluorescent intensity (MFI) signals detected in the serum or CSF samples and the MFI signal detected in the negative control samples. An anti-SARS-CoV-2 IgG ratio of $\geq 6$ in serum samples was considered positive (threshold set for diagnosis at the Lausanne University Hospital). The antibody index was calculated, for patients with available data, according to the Reiber's formula: Antibody index $=\mathrm{Q}_{\mathrm{SARS}-\mathrm{CoV}-2} / \mathrm{Q}_{\mathrm{IgG}}$ if $\mathrm{Q}_{\mathrm{IgG}}<\mathrm{Q}_{\mathrm{lim}}$ or $\mathrm{Q}_{\text {SARS-CoV-2 }} / \mathrm{Q}_{\text {lim }}$ if $\mathrm{Q}_{\mathrm{IgG}}>\mathrm{Q}_{\mathrm{lim}}$. $\mathrm{Q}_{\mathrm{lim}}$ was calculated as follows: $\mathrm{Q}_{\lim }(\mathrm{IgG})=\left(0.93\left[\mathrm{QAlb}^{2}+6 \times 10^{6}\right]^{0.5}-1.7\right) \times$ $10^{-3}$. An index of $\geq 1.5$ was considered as a hallmark of intrathecal synthesis.

\section{Cytokine Detection by Luminex Assay}

The concentration of cytokines/chemokines/growth factors in the serum and CSF was determined by multiplex bead assay (Thermofisher, Waltham, MA). The concentration of the following 49 soluble markers was assessed: interleukin (IL)1 $\alpha$, IL-1RA, IL-1 $\beta$, IL-2, IL-4, IL-5, IL-6, IL-7, IL-9, IL-10, IL12p70, IL-13, IL-15, IL-17A, IL-18, IL-21, IL-22, IL-23, IL-27, IL-31, interferon (IFN)- $\alpha$, IFN- $\gamma$, tumor necrosis factor (TNF) $\alpha$, CCL2 (MCP-1), CCL3 (MIP-1 $\alpha$ ), CCL4 (MIP$1 \beta)$, CCL5 (RANTES), CCL11 (eotaxin), CXCL1 (GRO$\alpha / \mathrm{KC}$ ), CXCL8 (IL-8), CXCL9 (MIG), CXCL10 (IP-10), CXCL12 (SDF-1 $\alpha$ ), CXCL13 (BLC), TNF $\beta$, NGF- $\beta$, BDNF, EGF, hepatocyte growth factor (HGF) FGF-2, LIF, PDGFBB, PlGF-1, SCF, VEGF-A, VEGF-D, BAFF, GM-CSF, and G-CSF. The assay was performed as per the manufacturer's instructions, as previously described. ${ }^{17}$ To reduce the variability related to multiple Luminex assays, only 2 big assays were run, the first one with half of the samples of the whole cohort of study patients and the second with the other half. Both assays included the same proportion of patients with severe COVID-19 in each assay (60\% of all patients with COVID in assay 1 vs $57 \%$ in assay 2 ).

\section{CSF/Serum Index}

Index for the enrichment of a given soluble factor in the CSF as compared to the serum was calculated to take into account 
Table 2 Clinical and CSF Characteristics of the Tested Cohort

\begin{tabular}{|c|c|c|c|c|}
\hline & SARS-CoV-2+ $(n=22)$ & IND $(n=21)$ & NIND (n = 19) & MS $(n=15)$ \\
\hline \multicolumn{5}{|l|}{ Demographic data } \\
\hline Age, mean [range] & $60.5[19-90]$ & 58 [22-92] & $54[24-84]$ & $39[28-51]$ \\
\hline \multicolumn{5}{|l|}{ Main neurologic diagnosis, $\mathbf{n}(\%)$} \\
\hline Headache, $\mathrm{n}(\%)$ & $4(18)$ & $1(4.8)$ & $3(16)$ & $0(0)$ \\
\hline Vascular/stroke, n (\%) & $0(0)$ & $1(4.8)$ & $2(10.5)$ & $0(0)$ \\
\hline Encephalitis/meningitis, $n$ (\%) & $2(9)$ & $15(66)$ & $0(0)$ & $0(0)$ \\
\hline Encephalopathy, n (\%) & $12(54)$ & $0(0)$ & $0(0)$ & $0(0)$ \\
\hline Neurodegenerative disease, $\mathrm{n}(\%)$ & $0(0)$ & $0(0)$ & $3(16)$ & $0(0)$ \\
\hline Myelitis, n (\%) & $1(4.5)$ & $0(0)$ & $0(0)$ & $0(0)$ \\
\hline Peripheral nerve, n (\%) & $2(9)$ & $3(14)$ & $4(21)$ & $0(0)$ \\
\hline MS, n (\%) & $0(0)$ & $0(0)$ & $0(0)$ & $15(100)$ \\
\hline Epilepsy, n (\%) & $0(0)$ & $0(0)$ & $1(5.3)$ & $0(0)$ \\
\hline Else, n (\%) & $1(4.5)$ & $1(4.8)$ & $6(31)$ & $0(0)$ \\
\hline
\end{tabular}

\section{CSF characteristics}

CSF proteins

\begin{tabular}{|c|c|c|c|c|}
\hline Level, mg/L, mean [range] & $484[264-715]$ & $1,479[309-10,588]$ & 402 [161-895] & 422 [264-594] \\
\hline Elevated (>400 mg/L), n (\%) & $13(59)$ & $18(86)$ & $8(42)$ & $8(53)$ \\
\hline \multicolumn{5}{|l|}{ Pleocytosis } \\
\hline Level, mean [range] & $3[0-21]$ & $71[0-540]$ & $0.95[0-4]$ & $15.6[0-51]$ \\
\hline Elevated $\left(\geq 5 / \mathrm{mm}^{3}\right), \mathrm{n}(\%)$ & $3(13)$ & $13(61)$ & $0(0)$ & $10(67)$ \\
\hline Elevated albumin ratio, $\mathbf{n}(\%)$ & 9/17 (53) & $15 / 19(78.9)$ & $2 / 16(12.5)$ & $3 / 15(20)$ \\
\hline Oligoclonal band pattern, $\mathrm{n}$ performed & 16 & 21 & 14 & 15 \\
\hline Type 1, n (\%) & $10(62)$ & $8(38)$ & $11(57)$ & $0(0)$ \\
\hline Type 2, n (\%) & $0(0)$ & $5(24)$ & $1(5)$ & $9(60)$ \\
\hline Type 3, n (\%) & $1(6)$ & $5(24)$ & $0(0)$ & $6(40)$ \\
\hline Type 4, n (\%) & $5(31)$ & $0(0)$ & $2(10.5)$ & $0(0)$ \\
\hline Type 5, n (\%) & $0(0)$ & $1(4.8)$ & $0(0)$ & $0(0)$ \\
\hline
\end{tabular}

Abbreviations: COVID-19 = coronavirus disease 2019; IgG = immunoglobulin G; IND = inflammatory neurologic disorder; NIND = noninflammatory neurologic disorder; SARS-CoV-2 = severe acute respiratory syndrome coronavirus 2.

Oligoclonal band pattern: type 1: normal CSF; type 2: oligoclonal IgG restricted to the CSF; type 3: identical IgG in the CSF and the serum with additional IgG bands restricted to the CSF; type 4: identical IgG bands in the CSF and serum; and type 5: monoclonal IgG bands in the CSF and serum (myeloma or monoclonal gammopathy of uncertain significance).

BBB opening as follows: (Factor CSF/serum)/(Albumin CSF/serum). Threshold positive for CXCL8 was set at 541 using the receiver operating curve (area under the receiver operating characteristics curve $0.79,95 \%$ CI $0.6036-0.9816, p$ $=0.0185$ ).

\section{Standard Protocol Approvals, Registrations, and Patient Consents}

This study was approved by the Canton de Vaud Ethical Committee (CER-VD) in the frame of the CORO-NEURO study (authorization no. 2020-01123) and the COOLINBRAIN study (authorization no. 2018-01622). All patients included in this study signed specific informed consent.

\section{Graphical Representation and Statistical Analysis}

Graphical representation and statistics were generated using PRISM software (version 8.1.2; GraphPad software, La Jolla, CA). A first unbiased analysis of the 49 parameters was performed using heatmap representation. K-means clustering 
(clustering distance: Canberra, clustering method: Ward) was made using the ClustVis web-based tool. ${ }^{18}$ Based on this unbiased analysis, some parameters of interest were chosen for individual analysis. To limit statistical jeopardy, we voluntarily limited the number of tested combinations. Multiple group analyses were made using nonparametric one-way analysis of variance followed by the Dunn multiple comparison test. For analysis with 2 groups, the Mann-Whitney test was used to determine statistical significance for continuous variables and the Fisher exact test for categorical variables.

\section{Data Availability}

Anonymized data will be made available on request from any qualified investigator.

\section{Results}

\section{Clinical Characteristics}

From March to November 2020, 38 patients benefited from a research of SARS-CoV-2 by RT-qPCR and had a concomitant lumbar puncture because of acute neurologic symptoms. Of those, 22 patients were diagnosed with COVID-19 based on the association of typical symptoms and positive laboratory tests (positive nasopharyngeal swab RT-qPCR [92\%] or serology [8\%]). Their neurologic symptoms could not be attributed to another condition than COVID-19 itself. As mentioned in the Methods, there were 3 additional patients with COVID-19 whose neurologic disorders were unrelated to COVID-19 (myelin oligodendrocyte-associated disorders, Lyme disease, and normal pressure hydrocephalus). To avoid any bias, they were not included in further analyses.

Clinical description of patients with SARS-CoV-2 is summarized in table 1 . These 22 patients presented with various neurologic presentations including encephalopathy (12), encephalitis (2), myelitis (1), optic neuritis (1), GuillainBarré syndrome (1), mononeuritis multiplex (1), and headache/vertigo (4).

More than half of them (13) were admitted to the ICU, including 9 who required mechanical ventilation. As compared to patients with moderate COVID, patients admitted to the ICU were older, had a higher body mass index, and suffered from more comorbidities. Most of these ICU patients presented with encephalopathy (11/13). Furthermore, some presented signs of critical illness myopathy/polyneuropathy, a diagnosis that was confirmed by nerve conduction studies for most of them $(6 / 8)$.

No prominent MRI abnormalities were found except in 1 patient who presented signs of vasculitis including T2 lesions, microbleeds, and diffusion restriction.

Most EEG recording performed (7/8) showed some abnormalities, consisting mainly in encephalopathic slowing but also irritative activity in 1 patient with encephalitis.

\section{CSF Characteristics}

The CSF of patients with COVID-19 was characterized mainly by the elevation of the protein level and elevated albumin ratio, indicating an opening of the $\mathrm{BBB}$. Oligoclonal bands were found in a minority of patients. In fact, most of the bands identified on isoelectrofocalization were shared between the serum and the CSF (type 4; table 2). Pleocytosis was encountered only in few patients $(3 / 22,13.6 \%$; range $\left.16-21 / \mathrm{mm}^{3}\right)$, all 3 with encephalitic or myelitis presentation. Of interest, a striking difference between patients with severe and moderate COVID-19 was the higher proportion of elevated albumin ratio in the former $(8 / 11,73 \%)$ than in the latter $(1 / 6,16 \%)(p=0.049)$.

As expected, the CSF profile was characterized by the high protein level and pleocytosis in most patients with IND and oligoclonal bands restricted to the CSF (type 2) in most patients with MS (table 2).

\section{SARS-CoV-2 RNA and Antibodies Detection in the Serum and CSF}

All 22 patients with COVID-19 underwent a RT-qPCR for the detection of SARS-CoV-2 RNA in the CSF. It came back negative in all, despite positivity for most (90\%) in the nasal swab (table 1).

Among patients who had a serologic test (14 patients), it came back positive for SARS-CoV-2 antibodies in the blood of $12(86 \%)$. The titers were high (mean ratio of 84.1 for a positivity threshold of $\geq 6$ ). The absence of anti-SARS-CoV$2 \mathrm{IgG}$ in the remaining 2 patients, contrasting with a positive nasal RT-qPCR, could be explained by the short time lapse between first symptoms and sampling ( 4 and 7 days, respectively). Conversely, 2 patients with IND had SARS CoV-2-specific antibodies slightly above the positive threshold in the blood (8.4 and 7.7, respectively, positivity threshold $\geq 6$ ) (figure $1 \mathrm{~B}$ ). Of note, these 2 patients presented with pathologies regularly associated with crossreactive antibodies: $\operatorname{sarcoidosis}^{19}$ and paraneoplastic syndrome. ${ }^{20}$

Antibodies against SARS-CoV-2 were detected in the CSF of 10 of 21 patients with COVID-19. Conversely, SARS-CoV-2 antibodies were not detected in the CSF of the 55 control study patients $(p<0.0001$; figure 1B). The antibody index was elevated in 5 of $8(62.5 \%)$ patients with severe COVID19 , suggesting intrathecal synthesis of antibodies directed against SARS-CoV-2 in some patients (figure 1C).

\section{Cytokines/Chemokines/Growth Factors in the Serum and CSF}

First, an unbiased analysis of the cytokine panel in the serum of patients with SARS-CoV-2, IND, NIND, and MS revealed 2 clusters. Most patients (9/11) with severe COVID-19 belonged to the inflammatory cluster (cluster 2) (figure 2A). We found a significant increase of IL-1RA, CXCL9, CXCL10, CXCL12, and HGF in the serum of severe SARS-CoV-2- 

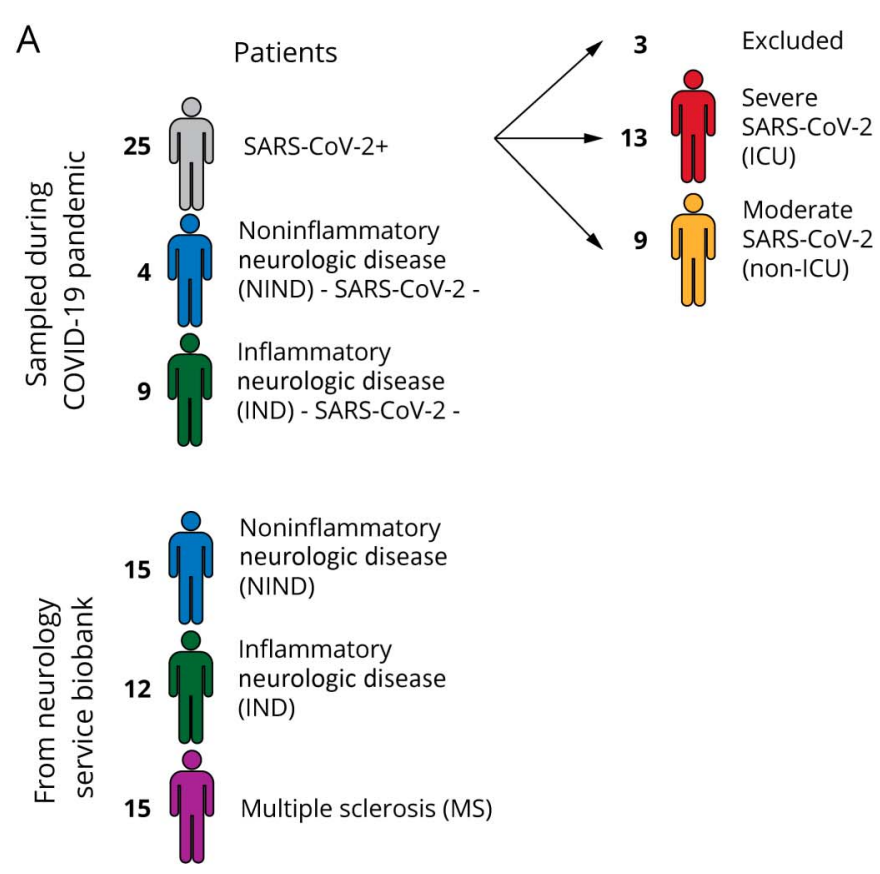

Samples

Analysis

Severe

SARS-COV-2

Moderate SARS-COV-2 (nOM-ICU)

B
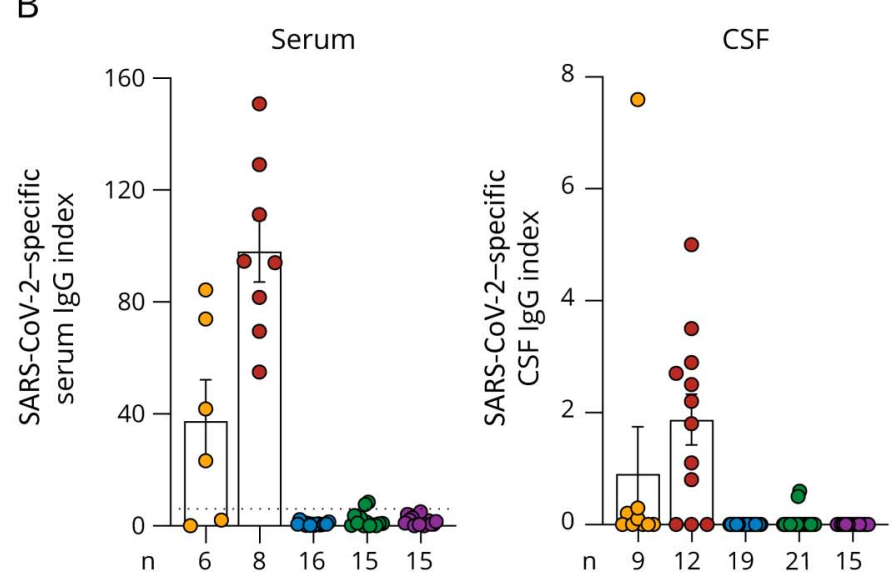

C

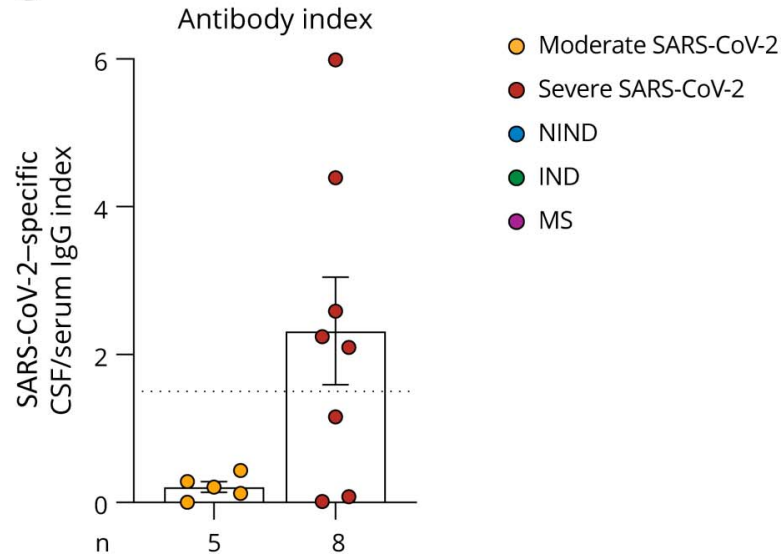

(A) Schematic representation of experimental design: Thirty-eight patients sampled during the COVID-19 pandemic and 42 from the biobank of the service of neurology (COOLIN'BRAIN) were tested for SARS-CoV-2 RNA expression and/or SARS-CoV-2 serology and/or Luminex assay for 49 cytokines/chemokines/ growth factors. Of note, the CSF +/- serum of all the 42 study patients who were part of COOLIN'BRAIN was harvested before January 2020 , thus before the arrival of SARS-CoV-2 in Switzerland. (B) Antibodies against SARS-CoV-2 detection in the serum and/or the CSF of patients with moderate SARS-CoV- 2 infection (yellow circles, $\mathrm{n}=6$ for serum and $\mathrm{n}=9$ for CSF), severe SARS-CoV-2 infection (red circles, $\mathrm{n}=8$ for serum and $\mathrm{n}=12$ for CSF), IND (green circles, $\mathrm{n}=14$ for serum and $n=23$ for CSF), NIND (blue circles, $n=16$ for serum and $n=21$ for CSF), and MS (purple circles, $n=15$ for serum and $n=15$ for CSF). (C) The antibody index was calculated following the Reiber formula for patients for whom we had concomitant serum and CSF data, thus 5 moderate SARS-CoV-2 infection (yellow circles), 8 severe SARS-CoV-2 infection (red circles). The dotted line represents the threshold for an intrathecal synthesis (antibody index $\geq 1.5)$. COVID19 = coronavirus disease 2019; ICU = intensive care unit; IND = inflammatory neurologic disorder; NIND = noninflammatory neurologic disorder; SARS-CoV-2 = severe acute respiratory syndrome coronavirus 2.

infected patients as compared to moderate ones (figure 2B). In addition, we also found elevated IL-6 levels $(>11 \mathrm{pg} / \mathrm{mL})$ in 7 of $11(63.6 \%)$ sera of patients with severe COVID-19 vs only 1 of 5 (20\%) sera of patients with moderate COVID-19 (figure 2B). These findings recapitulate the inflammatory profile of patients with COVID-19 already identified by others. ${ }^{21,22}$ Similarly, all these cytokines except CXCL12 were also increased in the serum of SARS-CoV-2-infected patients compared with neurologic control patients (MS, IND, and NIND) (figure e-1, links.lww.com/NXI/A499).
Although SARS-CoV-2-infected patients with neurologic conditions were displaying increased inflammatory mediators in the serum, this was not the case in the CSF. Indeed, analyses performed in this compartment revealed that SARSCoV-2-infected patients were mainly clustered with NIND and MS ones, whereas the CSF of patients with IND exhibited a strong immune signature, characterized by elevated levels of several cytokines, chemokines, and growth factors (figure 3A). This unbiased clustering was confirmed by individual cytokine/chemokine analysis with a significant elevation of 


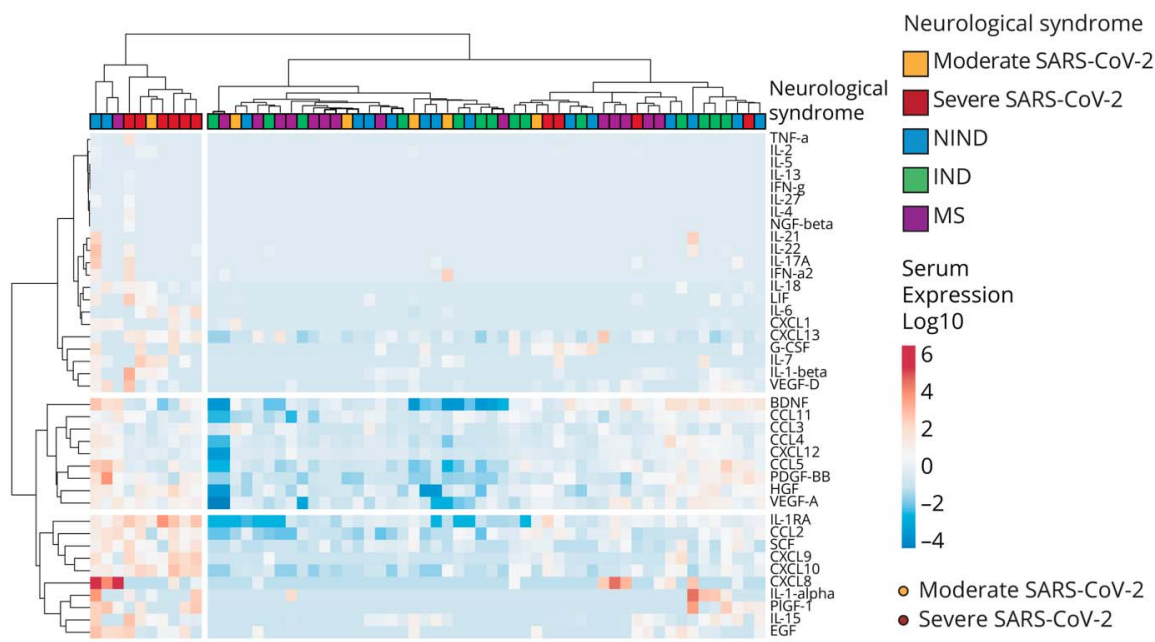

B
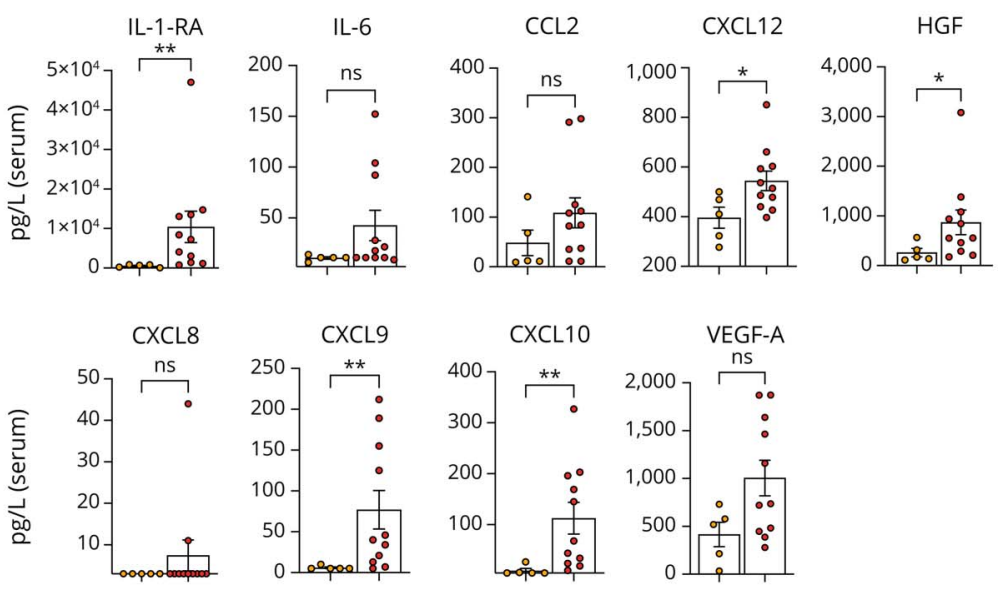

(A) Unbiased heatmap comparisons of cytokines/chemokines/growth factors within the serum of SARS-CoV-2infected patients and patients with IND, MS, and NIND. Expression is represented in $\log 10$ scale. K-means clustering was used to determine patients clusters (cluster 1, $\mathrm{n}=42$; cluster 2, $\mathrm{n}=$ 19). Cytokines/chemokines/growth factors with no variations across all patients are not displayed. (B) Bar plot representation (mean + SEM) of IL-1RA IL-6, CCL2， CXCL8， CXCL9, CXCL10, CXCL12, HGF, and VEGF-A expression in the serum of patients with severe $(n=$ 11 , red circles) or moderate $(n=5$, yellow circles) SARS-CoV-2 infection. Statistical significance was calculated using the Mann-Whitney test (ns: not significant, adjusted $p: \quad * \leq 0.05, \quad * * \leq 0.01$ $* \star * \leq 0.001$, and $* \star \star * \leq 0.001$ ). COVID-19 = coronavirus disease 2019; IND = inflammatory neurologic disorder; NIND $=$ noninflammatory neurologic disorder; SARS-CoV-2 = severe acute respiratory syndrome coronavirus 2 .
IL-1RA, IL-6, CCL4, CCL5, CXCL8, CXCL9, CXCL10, CXCL12, CXCL13, and G-CSF in the CSF of patients with IND as compared to the one of patients with NIND (figure 3B and data not shown). Even if they did not display as strong an immune signature as patients with IND, patients with MS showed higher levels of CXCL10, CXCL12, CXCL13, and G-CSF in the CSF (figure 3B and data not shown) than NIND controls. Of note, patients with severe COVID-19 displayed a significant increase of CXCL8 as compared to NIND but did not display a significant change of any of the other factors as compared to any other categories of study patients, except for patients with moderate SARS-CoV-2 (see below).

Accordingly, the clustering based on all inflammatory mediators did not allow to discriminate severe from moderate COVID-19 patients, thus demonstrating the absence of the cytokine storm in the CSF (figure $3 \mathrm{~A}$ ). Yet, of interest, by individual cytokine/chemokine/growth factor analysis, we found 3 mediators differentially expressed between patients with moderate and severe SARS-CoV-2: CXCL8, CCL2, and VEGF-A (figure 3B). Of interest, the levels of CXCL8 and
VEGF-A tended to be higher in the CSF of SARS-CoV-2infected patients with encephalopathy, $85 \%$ of them belonging to the ICU group (figure e-2A, links.lww.com/NXI/A499).

As mentioned above, the proportion of patients with an elevated albumin ratio was significantly higher in patients with severe than in patients with moderate COVID-19. We thus investigated the relationship between this index and the CSF levels of CXCL8, CCL2, and VEGF-A. We observed that CXCL8 was significantly higher in the CSF of patients with an elevated albumin ratio, although VEGF-A almost reached statistical significance $(p=0.059)$, but CCL2 showed no difference (figure $3 \mathrm{C}$ and data not shown). Because an elevated albumin ratio is a sign of BBB opening, we next looked at the correlation of CXCL8, VEGF-A, and CCL2 levels in the serum and CSF. CXCL8 was undetectable in the serum of patients with COVID-19, except for only 2 of them (figure 2B). The CXCL8 CSF/serum index was elevated in 6 of 9 severe patients against 0 of 5 in milder forms $(p=0.0310$, Fisher exact test), suggesting intrathecal synthesis (figure e2C, links.lww.com/NXI/A499). 
A

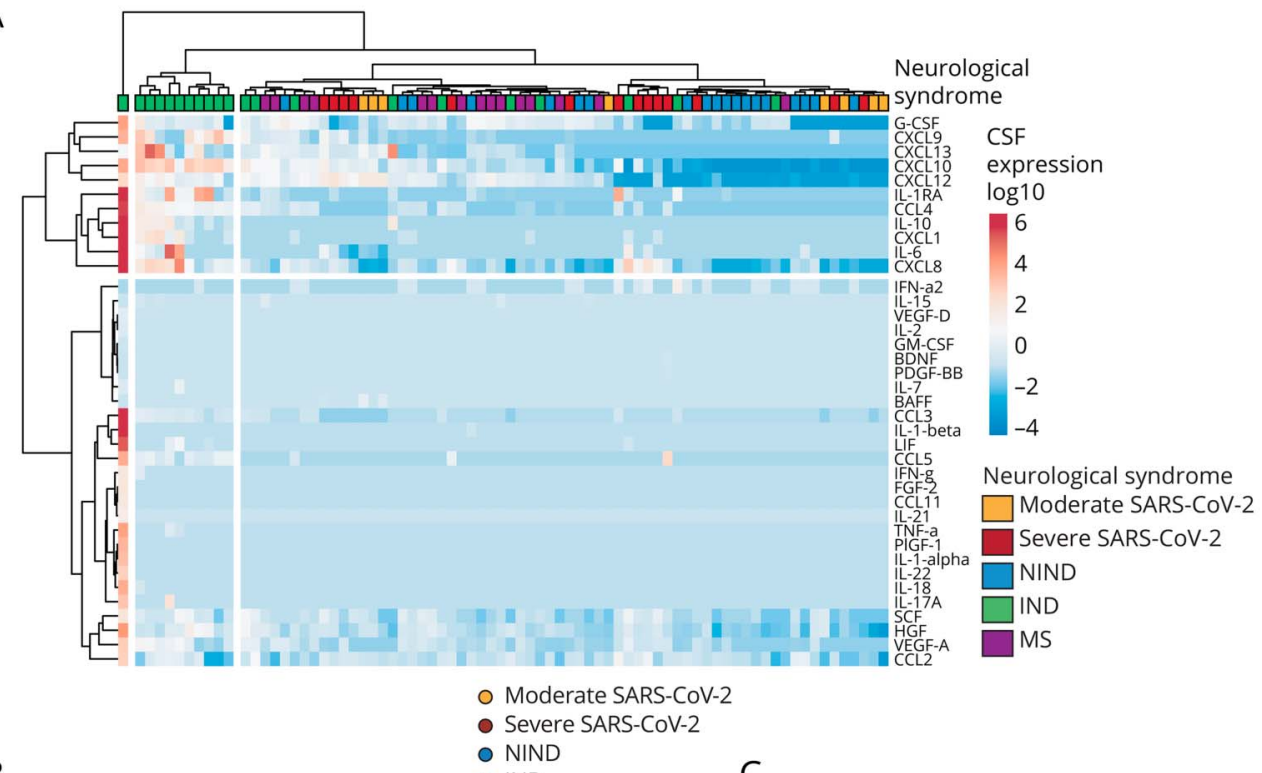

B

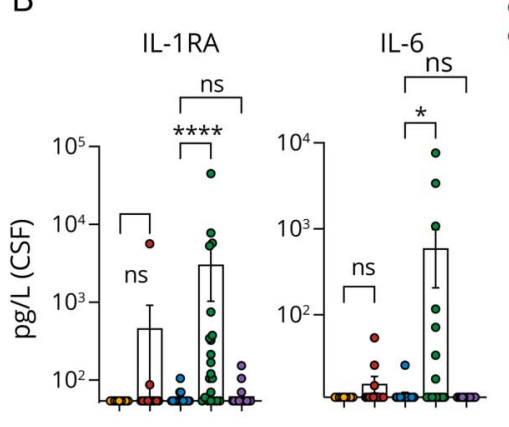

- NIND

- MS CCL2
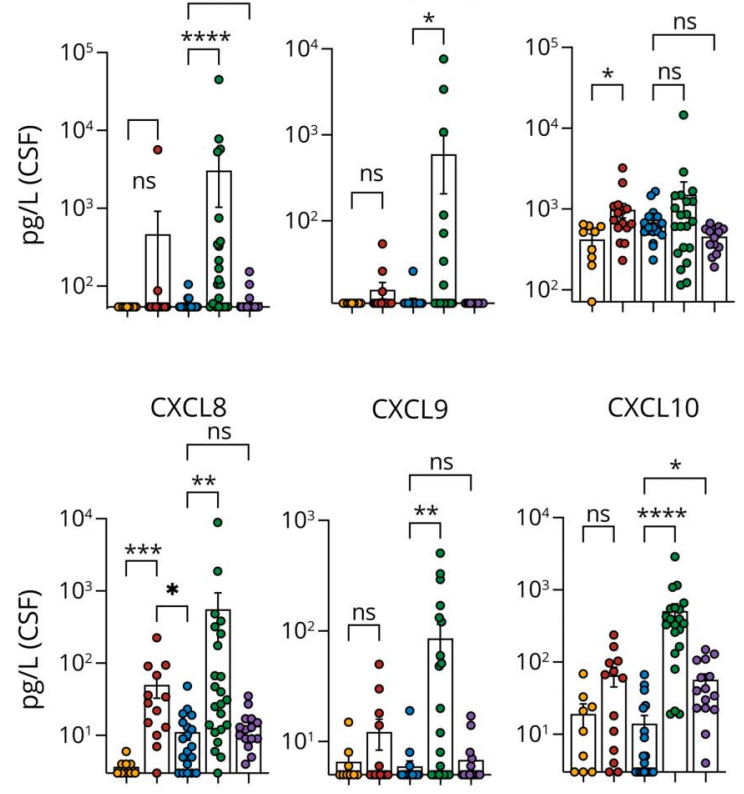

CXCL10

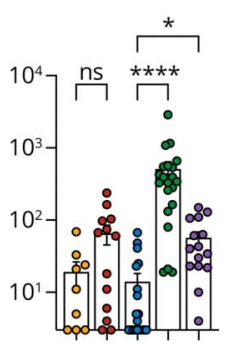

CXCL12
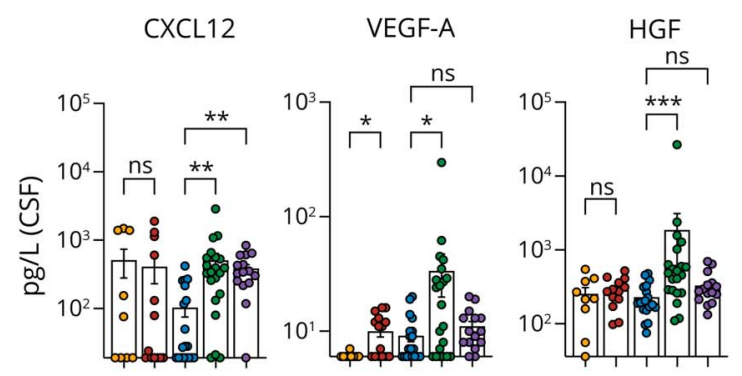

C
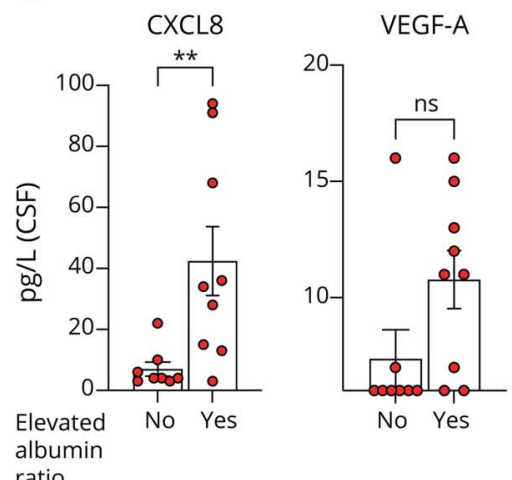

ratio

D
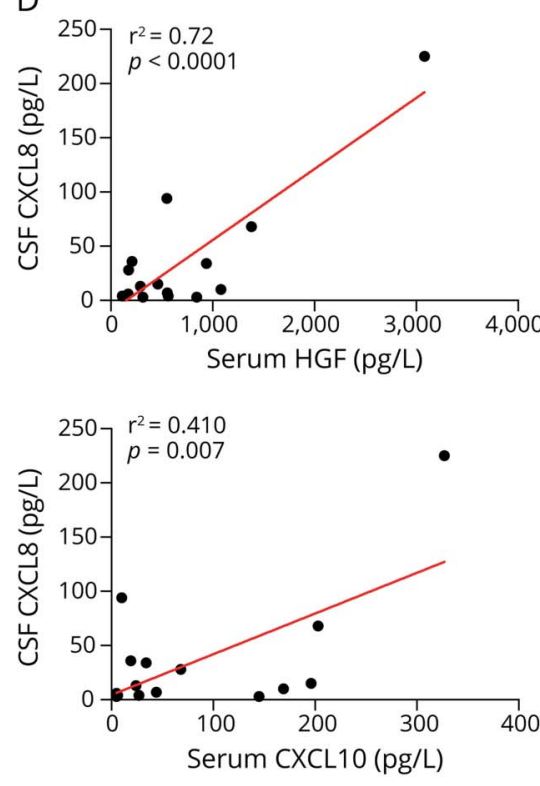

(A) Unbiased heatmap comparisons of cytokines/chemokines and growth factors within the CSF of SARS-CoV-2-infected (severe or moderate) and SARS-CoV-2uninfected patients, i.e., patients with IND, NIND, and MS. Expression is represented in log10 scale. $\mathrm{K}$-means clustering was used to determine patients' clusters (cluster $1, n=1$; cluster $2, n=10$; cluster $3, n=66$ ). Cytokines/chemokines/ growth factors with no variations across all patients are not displayed. (B) Bar plot representation (mean \pm SEM) with $\log 10$ scale of IL-1RA, IL-6, CCL2, CXCL8, CXCL9, CXCL10, CXCL12, HGF, and VEGF-A expression in the CSF of patients with severe SARS-CoV-2 (red circles, $n=13$ ), moderate SARS-CoV2 (yellow circles, $n=9$ ), IND (green circles, $n=21$ ), NIND (blue circles, $n=19$ ), or MS (purple circles, $n=$ 15). Statistical significance calculated using nonparametric oneway analysis of variance followed by the Dunn multiple comparison test; all comparisons performed are displayed (adjusted $p:{ }^{*} \leq 0.05$, $* * \leq 0.01 \quad * * * \leq 0.001$ and $* \star * * \leq 0.001)$. (C) Representation of the expression of CXCL8 and VEGF-A in patients with COVID-19 with an elevated albumin ratio $(n=$ 9 ) or not $(n=8)$. Statistical significance was calculated using the Mann-Whitney test ( $* * p \leq 0.01)$. (D) Linear regression of CXCL8 in the CSF compared with serum HGF (top panel) and serum CXCL10 (bottom panel). COVID-19 = coronavirus disease 2019; IND = inflammatory neurologic disorder; NIND = noninflammatory neurologic disorder; ns = not significant; SARS-CoV-2 $=$ severe acute respiratory syndrome coronavirus 2 .
Serum levels of VEGF-A did not show any correlation with the CSF ones $\left(r^{2}=0.004, p\right.$ value $\left.=0.65\right)$, whereas there was a trend for a correlation of CCL2 concentrations between the 2 compartments $\left(r^{2}=0.22, p\right.$ value $=0.06$; figure $\mathrm{e}-2 \mathrm{~B}$, links. lww.com/NXI/A499). Yet, the CSF/serum index did not display increased enrichment of VEGF-A or CCL2 in the CSF 
of patients with severe COVID-19 as compared to patients with moderate COVID-19 or NIND (figure e-2C). Of note, concentrations of CXCL8 and VEGF-A in the CSF correlated together (figure e-2D), reinforcing the idea that secretion of these factors is linked in the COVID-19 context.

Finally, we found that an increased serum level of CXCL10 and HGF was correlated with an increased CSF concentration of CXCL8 (figure 2E).

\section{Discussion}

In this study, we attempted to understand the pathogenesis of neurologic impairments in the context of COVID-19 disease.

First, we did not detect SARS-CoV-2 RNA in the CSF of any of our 22 patients. Most authors addressing the question also report the absence of evidence of viral dissemination in the brain of patients with COVID-19, thus ruling out this causality in most COVID-19-associated neurologic disorders. However, we found that about half of SARS-CoV-2-infected patients exhibited virus-specific antibodies in their CSF. We were also able to show that several patients with severe COVID-19 exhibited an intrathecal synthesis of SARS-CoV2-specific antibodies. Of note, the authors recently showed that the CSF from a patient with COVID-19 displayed neutralizing antibodies able to prevent neuronal infection in an hiPSC-derived brain organoid model. ${ }^{23}$

Most importantly, our cohort composed of both severe and moderate patients with paired CSF and serum samples allowed us to study the relationship between peripheral inflammation, neuroinflammation, and neurologic complications in both subgroups of patients with COVID-19. First, we were able to show that SARS-CoV-2-infected patients, even with a severe disease, do not display a cytokine storm in the CSF despite their sera being the most inflammatory of all 4 groups of study patients. Of note, these patients exhibit an inflammatory profile in the serum similar to what was reported by several groups, ${ }^{21,22}$ thus ruling out that our samples would have been collected after the resolution of the inflammation.

Our findings are in line with a previous report showing low concentrations of IL-6, IL-10, and IFN $\gamma$ in the CSF of SARSCoV-2-infected patients with neurologic complications. ${ }^{24}$ However, to the best of our knowledge, no other authors have looked so far at such an extensive number of inflammatory mediators, nor have they included such selected control cohorts of study patients with paired CSF/serum samples allowing the assessment of soluble factors in both compartments at the same time.

Of interest, we could show that patients with severe COVID19 exhibited higher CSF levels of CXCL8, CCL2, and VEGFA than SARS-CoV-2 patients with a moderate disease. In particular, patients suffering from an encephalopathy displayed the highest levels of VEGF-A and CXCL8. Most importantly, despite evidence of $\mathrm{BBB}$ disruption, we found striking evidence of intrathecal CXCL8 production in severe patients. Yet, CXCL8 has recently been associated with neurologic complications in severe COVID-19. ${ }^{25,26}$

In our study, CXCL8 and VEGF-A were also associated with an increased albumin ratio, thus linking these mediators with a dysfunction of the neurovascular unit (brain endothelium and astrocytes). In the brain, CXCL8 is produced by astrocytes, microglia, and endothelial cells, and VEGF-A is known to be produced by astrocytes and endothelial cells. Both factors are able to impair the BBB function. ${ }^{27,28}$ Precisely, microvascular injuries in the brain are a key feature in patients with severe COVID-19. ${ }^{29}$

Following this line of evidence, previous reports have found elevated levels of glial fibrillary acidic protein, chitinase-like-3 protein 1, and soluble triggering receptor expressed on myeloid cells 2 pointing to an enhanced astrocyte and microglial reactivity in patients with severe COVID-19 with neurologic complications. $^{10,25,30-32}$ Yet, when activated, these glial cells can lead to the disruption of the BBB through both soluble factor production and reduction of astrocytic gap junctions, among other mechanisms. Integrating our findings with what is known in the literature, we propose that in patients with COVID-19 encephalopathy, there is an increased astrocytic and microglial reactivity leading to a disruption of the $\mathrm{BBB}$.

COVID-19-associated encephalopathies share a number of common points with other encephalopathies associated with a systemic syndrome, such as sepsis-associated encephalopathies (SAEs) and ICU-associated delirium. Of interest, these patients also harbor BBB dysfunction, ${ }^{33}$ which is instrumental in causing the related encephalopathies. If $\mathrm{BBB}$ dysfunction in SAE is commonly believed to be directly triggered by peripheral inflammation, ${ }^{33}$ precipitating factors in ICU-associated delirium strongly involve systemic metabolic alterations (hypoglycemia and metabolic acidosis) and hypoxia as key triggers of delirium. ${ }^{34}$ In particular, it is known that hypoxia has strong disrupting effects on the neurovascular unit. Indeed, experimental models have demonstrated that hypoxia causes the production of CXCL8, CCL2, and VEGF-A with discrete production of other inflammatory cytokines, ${ }^{35}$ thus mirroring our data from patients. Precisely, hypoxia was present in all patients classified here as severe, with 9 of $13(69 \%)$ requiring mechanical ventilation.

Finally, we did not find any statistical correlation between the identified encephalopathy markers CXCL8 and VEGF-A in the CSF and inflammatory markers from the serum, except from CXCL10. However, CSF CXCL8 levels were correlated with serum HGF. HGF is an instrumental growth factor for tissue repair secreted in response to tissue damage. Its concentration in the serum has been proposed as a prognostic 
biomarker in severe SARS-CoV-2 infection. ${ }^{22}$ In this context, HGF increase seems to appear as a consequence of inflammation and may be a reflection of tissue damage induced by the peripheral cytokine increase.

We may point to a limited number of tested patients and larger series could help decipher the mechanisms at play in the various conditions encountered in COVID-19. We also lack longitudinal follow-up that could help explain long-haul neurologic presentations. However, because of large recruitment criteria, our results could be applicable to most patients with COVID-19.

To conclude, our results suggest that encephalopathies in severe SARS-CoV-2-infected patients are not due to a major viral infection of the brain, nor due to a leakage of the cytokine storm from the periphery into the CNS. However, we identify a strong link between encephalopathies and BBB impairment. Taken together, our study identifies a potential mechanism by which the activation of neurovascular unit cells leads to barrier disruption, as a result of peripheral inflammation and/or hypoxia. The fact that COVID-19-associated encephalopathies respond to corticosteroids actually supports this hypothesis. ${ }^{12,13}$

\section{Acknowledgment}

The authors are grateful to Mrs. Le Goff, Do Rosario, Felix, and Gran for their technical help and for collecting study subject samples. The authors are also indebted to Prof. Braissant and Dr. Opota.

\section{Study Funding}

This work was made possible by grants to RDP from the Swiss National Science Foundation 320030-179531 and from the Swiss Multiple Sclerosis Foundation.

\section{Disclosure}

The authors have nothing to disclose regarding the subject of this study. Go to Neurology.org/NN for full disclosures.

\section{Publication History}

Received by Neurology: Neuroimmunology \& Neuroinflammation February 10, 2021. Accepted in final form May 4, 2021.

Appendix Authors

\begin{tabular}{|c|c|c|}
\hline Name & Location & Contribution \\
\hline $\begin{array}{l}\text { Raphael } \\
\text { Bernard- } \\
\text { Valnet, MD, } \\
\text { PhD }\end{array}$ & $\begin{array}{l}\text { Centre Hospitalier } \\
\text { Universitaire Vaudois, } \\
\text { Lausanne, Switzerland }\end{array}$ & $\begin{array}{l}\text { Design and conceptualized } \\
\text { the study; analyzed the data; } \\
\text { and drafted the manuscript } \\
\text { for intellectual content }\end{array}$ \\
\hline $\begin{array}{l}\text { Sylvain } \\
\text { Perriot, } \\
\text { PharmD, PhD }\end{array}$ & $\begin{array}{l}\text { Centre Hospitalier } \\
\text { Universitaire Vaudois, } \\
\text { Lausanne, Switzerland }\end{array}$ & $\begin{array}{l}\text { Design and conceptualized } \\
\text { the study; analyzed the data; } \\
\text { and drafted the manuscript } \\
\text { for intellectual content }\end{array}$ \\
\hline $\begin{array}{l}\text { Mathieu } \\
\text { Canales, MSc }\end{array}$ & $\begin{array}{l}\text { Centre Hospitalier } \\
\text { Universitaire Vaudois, } \\
\text { Lausanne, Switzerland }\end{array}$ & $\begin{array}{l}\text { Collected the data and } \\
\text { analyzed the data }\end{array}$ \\
\hline
\end{tabular}

Appendix (continued)

\begin{tabular}{|c|c|c|}
\hline Name & Location & Contribution \\
\hline $\begin{array}{l}\text { Beatrice } \\
\text { Pizzarotti, MD }\end{array}$ & $\begin{array}{l}\text { Centre Hospitalier } \\
\text { Universitaire Vaudois, } \\
\text { Lausanne, Switzerland }\end{array}$ & Collected the data \\
\hline $\begin{array}{l}\text { Leonardo } \\
\text { Caranzano, } \\
\text { MD }\end{array}$ & $\begin{array}{l}\text { Centre Hospitalier } \\
\text { Universitaire Vaudois, } \\
\text { Lausanne, Switzerland }\end{array}$ & Collected the data \\
\hline $\begin{array}{l}\text { Mayté Castro- } \\
\text { Jiménez, MD }\end{array}$ & $\begin{array}{l}\text { Centre Hospitalier } \\
\text { Universitaire Vaudois, } \\
\text { Lausanne, Switzerland }\end{array}$ & Collected the data \\
\hline $\begin{array}{l}\text { Jean-Benoit } \\
\text { Epiney, MD }\end{array}$ & $\begin{array}{l}\text { Centre Hospitalier } \\
\text { Universitaire Vaudois, } \\
\text { Lausanne, Switzerland }\end{array}$ & Collected the data \\
\hline $\begin{array}{l}\text { Sergiu Vijiala, } \\
\text { MD }\end{array}$ & $\begin{array}{l}\text { Centre Hospitalier } \\
\text { Universitaire Vaudois, } \\
\text { Lausanne, Switzerland }\end{array}$ & Collected the data \\
\hline $\begin{array}{l}\text { Paolo } \\
\text { Salvioni- } \\
\text { Chiabotti, } \\
\text { MD, MSc }\end{array}$ & $\begin{array}{l}\text { Centre Hospitalier } \\
\text { Universitaire Vaudois, } \\
\text { Lausanne, Switzerland }\end{array}$ & Collected the data \\
\hline $\begin{array}{l}\text { Angelica } \\
\text { Anichini, MD }\end{array}$ & $\begin{array}{l}\text { Centre Hospitalier } \\
\text { Universitaire Vaudois, } \\
\text { Lausanne, Switzerland }\end{array}$ & Collected the data \\
\hline $\begin{array}{l}\text { Alexander } \\
\text { Salerno, MD }\end{array}$ & $\begin{array}{l}\text { Centre Hospitalier } \\
\text { Universitaire Vaudois, } \\
\text { Lausanne, Switzerland }\end{array}$ & Collected the data \\
\hline $\begin{array}{l}\text { Katia Jaton, } \\
\text { MD, PhD }\end{array}$ & $\begin{array}{l}\text { Centre Hospitalier } \\
\text { Universitaire Vaudois, } \\
\text { Lausanne, Switzerland }\end{array}$ & $\begin{array}{l}\text { Collected the data and revised } \\
\text { the manuscript for intellectual } \\
\text { content }\end{array}$ \\
\hline $\begin{array}{l}\text { Julien } \\
\text { Vaucher, MD }\end{array}$ & $\begin{array}{l}\text { Centre Hospitalier } \\
\text { Universitaire Vaudois, } \\
\text { Lausanne, Switzerland }\end{array}$ & $\begin{array}{l}\text { Revised the manuscript for } \\
\text { intellectual content }\end{array}$ \\
\hline $\begin{array}{l}\text { Matthieu } \\
\text { Perreau, PhD }\end{array}$ & $\begin{array}{l}\text { Centre Hospitalier } \\
\text { Universitaire Vaudois, } \\
\text { Lausanne, Switzerland }\end{array}$ & $\begin{array}{l}\text { Analyzed the data and drafted } \\
\text { the manuscript for intellectual } \\
\text { content }\end{array}$ \\
\hline $\begin{array}{l}\text { Gilbert } \\
\text { Greub, MD, } \\
\text { PhD }\end{array}$ & $\begin{array}{l}\text { Centre Hospitalier } \\
\text { Universitaire Vaudois, } \\
\text { Lausanne, Switzerland }\end{array}$ & $\begin{array}{l}\text { Revised the manuscript for } \\
\text { intellectual content }\end{array}$ \\
\hline $\begin{array}{l}\text { Giuseppe } \\
\text { Pantaleo, MD }\end{array}$ & $\begin{array}{l}\text { Centre Hospitalier } \\
\text { Universitaire Vaudois, } \\
\text { Lausanne, Switzerland }\end{array}$ & $\begin{array}{l}\text { Revised the manuscript for } \\
\text { intellectual content }\end{array}$ \\
\hline $\begin{array}{l}\text { Renaud A. Du } \\
\text { Pasquier, MD }\end{array}$ & $\begin{array}{l}\text { Centre Hospitalier } \\
\text { Universitaire Vaudois, } \\
\text { Lausanne, Switzerland }\end{array}$ & $\begin{array}{l}\text { Design and conceptualized } \\
\text { the study and revised the } \\
\text { manuscript for intellectual } \\
\text { content }\end{array}$ \\
\hline
\end{tabular}

\section{References}

1. Gu J, Gong E, Zhang B, et al. Multiple organ infection and the pathogenesis of SARS. J Exp Med. 2005;202(3):415-424.

2. Hung EC, Chim SS, Chan PK, et al. Detection of SARS coronavirus RNA in the cerebrospinal fluid of a patient with severe acute respiratory syndrome. Clin Chem. 2003;49(12):2108-2109.

3. Arabi YM, Harthi A, Hussein J, et al. Severe neurologic syndrome associated with Middle East respiratory syndrome corona virus (MERS-CoV). Infection. 2015;43(4): 495-501.

4. Helms J, Kremer S, Merdji H, et al. Neurologic features in severe SARS-CoV-2 infection. N Engl J Med. 2020;382(23):2268-2270.

5. Giacomelli A, Pezzati L, Conti F, et al. Self-reported olfactory and taste disorders in SARS-CoV-2 patients: a cross-sectional study. Clin Infect Dis. 2020;71(15):889-890.

6. Bernard-Valnet R, Pizzarotti B, Anichini A, et al. Two patients with acute meningoencephalitis concomitant with SARS-CoV-2 infection. Eur J Neurol. 2020;27(9):e43-e44.

7. Toscano G, Palmerini F, Ravaglia $S$, et al. Guillain-Barre syndrome associated with SARS-CoV-2. N Engl J Med. 2020;382(26):2574-2576. 
8. Oxley TJ, Mocco J, Majidi S, et al. Large-vessel stroke as a presenting feature of covid19 in the young. N Engl J Med. 2020;382(20):e60.

9. Lewis A, Frontera J, Placantonakis DG, et al. Cerebrospinal fluid in COVID-19: a systematic review of the literature. J Neurol Sci. 2021;421:117316.

10. Matschke J, Lutgehetmann M, Hagel C, et al. Neuropathology of patients with COVID19 in Germany: a post-mortem case series. Lancet Neurol. 2020;19(11):919-929.

11. Franke C, Ferse C, Kreye J, et al. High frequency of cerebrospinal fluid autoantibodies in COVID-19 patients with neurological symptoms. Brain Behav Immun. 2021;93: 415-419.

12. Pugin D, Vargas MI, Thieffry C, et al. COVID-19-related encephalopathy responsive to high doses glucocorticoids. Neurology. 2020;95(12):543-546.

13. Cao A, Rohaut B, Le Guennec L, et al. Severe COVID-19-related encephalitis can respond to immunotherapy. Brain. 2020;143(12):e102.

14. Corman VM, Landt O, Kaiser M, et al. Detection of 2019 novel coronavirus (2019$\mathrm{nCoV}$ ) by real-time RT-PCR. Euro Surveill. 2020;25(3):2000045.

15. Opota O, Brouillet R, Greub G, Jaton K. Comparison of SARS-CoV-2 RT-PCR on a high-throughput molecular diagnostic platform and the cobas SARS-CoV-2 test for the diagnostic of COVID-19 on various clinical samples. Pathog Dis. 2020;78(8): ftaa01.

16. Fenwick C, Croxatto A, Coste AT, et al. Changes in SARS-CoV-2 Spike versus nucleoprotein antibody responses impact the estimates of infections in populationbased seroprevalence studies. J Virol. 2021;95(3):e01828-20.

17. Perriot S, Mathias A, Perriard G, et al. Human induced pluripotent stem cell-derived astrocytes are differentially activated by multiple sclerosis-associated cytokines. Stem Cel Rep. 2018;11(5):1199-1210.

18. Metsalu T, Vilo J. ClustVis: a web tool for visualizing clustering of multivariate data using principal component analysis and heatmap. Nucleic Acids Res. 2015;43(W1): W566-W570.

19. Grunewald J, Grutters JC, Arkema EV, Saketkoo LA, Moller DR, Muller-Quernheim J. Sarcoidosis. Nat Rev Dis Primers. 2019;5(1):45.

20. Pelosof LC, Gerber DE. Paraneoplastic syndromes: an approach to diagnosis and treatment. Mayo Clin Proc. 2010;85(9):838-854.

21. Del Valle DM, Kim-Schulze S, Huang HH, et al. An inflammatory cytokine signature predicts COVID-19 severity and survival. Nat Med. 2020;26(10):1636-1643.

22. Young BE, Ong SWX, Ng LFP, et al. Viral dynamics and immune correlates of COVID-19 disease severity. Clin Infect Dis. 2020;28:ciaa1280.
23. Song E, Zhang C, Israelow B, et al. Neuroinvasive potential of SARS-CoV-2 revealed in a human brain organoid model. bioRxiv 2020:2020.06.25.169946.

24. Helms J, Kremer S, Merdji H, et al. Delirium and encephalopathy in severe COVID19: a cohort analysis of ICU patients. Crit Care. 2020;24(1):491.

25. Pilotto A, Masciocchi S, Volonghi I, et al. SARS-CoV-2 encephalitis is a cytokine release syndrome: evidences from cerebrospinal fluid analyses. Clin Infect Dis. 2021;4: ciaa1933.

26. Espindola OM, Gomes YCP, Brandao CO, et al. Inflammatory cytokine patterns associated with neurological diseases in coronavirus disease 2019. Ann Neurol. 2021; 102(5):155-162.

27. Haarmann A, Schuhmann MK, Silwedel C, Monoranu CM, Stoll G, Buttmann M Human brain endothelial CXCR2 is inflammation-inducible and mediates CXCL5 and CXCL8-triggered paraendothelial barrier breakdown. Int J Mol Sci. 2019;20(3): 602.

28. Shimizu F, Sano Y, Tominaga O, Maeda T, Abe MA, Kanda T. Advanced glycation end-products disrupt the blood-brain barrier by stimulating the release of transforming growth factor- $\beta$ by pericytes and vascular endothelial growth factor and matrix metalloproteinase-2 by endothelial cells in vitro. Neurobiol Aging. 2013;34(7): 1902-1912.

29. Lee MH, Perl DP, Nair G, et al. Microvascular injury in the brains of patients with Covid-19. N Engl J Med. 2021;384(5):481-483.

30. Perrin P, Collongues N, Baloglu S, et al. Cytokine release syndrome-associated encephalopathy in patients with COVID-19. Eur J Neurol. 2021;28(1):248-258.

31. Kanberg N, Ashton NJ, Andersson LM, et al. Neurochemical evidence of astrocytic and neuronal injury commonly found in COVID-19. Neurology. 2020;95(12): e1754-e1759.

32. Deigendesch N, Sironi L, Kutza M, et al. Correlates of critical illness-related encephalopathy predominate postmortem COVID-19 neuropathology. Acta Neuropathol. 2020;140(4):583-586.

33. Chaudhry N, Duggal AK. Sepsis associated encephalopathy. Adv Med. 2014;2014 762320.

34. Wilson JE, Mart MF, Cunningham C, et al. Delirium. Nat Rev Dis Primers. 2020;6(1) 90.

35. Nzou G, Wicks RT, VanOstrand NR, et al. Multicellular 3D neurovascular unit model for assessing hypoxia and neuroinflammation induced blood-brain barrier dysfunction. Sci Rep. 2020;10(1):9766. 


\title{
Neurology \\ Neuroimmunology \& Neuroinflammation
}

\author{
Encephalopathies Associated With Severe COVID-19 Present Neurovascular Unit \\ Alterations Without Evidence for Strong Neuroinflammation \\ Raphael Bernard-Valnet, Sylvain Perriot, Mathieu Canales, et al. \\ Neurol Neuroimmunol Neuroinflamm 2021;8; \\ DOI 10.1212/NXI.0000000000001029
}

This information is current as of June 16, 2021

\begin{abstract}
Updated Information \&
Services

including high resolution figures, can be found at:

http://nn.neurology.org/content/8/5/e1029.full.html

References

This article cites 34 articles, 3 of which you can access for free at: http://nn.neurology.org/content/8/5/e1029.full.html\#\#ref-list-1

Citations

This article has been cited by 1 HighWire-hosted articles:

http://nn.neurology.org/content/8/5/e1029.full.html\#\#otherarticles

Subspecialty Collections

This article, along with others on similar topics, appears in the following collection(s):

COVID-19

http://nn.neurology.org//cgi/collection/covid_19

Critical care

http://nn.neurology.org//cgi/collection/critical_care

Delirium

http://nn.neurology.org//cgi/collection/delirium

Permissions \& Licensing

Information about reproducing this article in parts (figures,tables) or in its entirety can be found online at:

http://nn.neurology.org/misc/about.xhtml\#permissions

Reprints

Information about ordering reprints can be found online:

http://nn.neurology.org/misc/addir.xhtml\#reprintsus

Neurol Neuroimmunol Neuroinflamm is an official journal of the American Academy of Neurology.

Published since April 2014, it is an open-access, online-only, continuous publication journal. Copyright

Copyright $\odot 2021$ The Author(s). Published by Wolters Kluwer Health, Inc. on behalf of the American

Academy of Neurology.. All rights reserved. Online ISSN: 2332-7812.
\end{abstract}

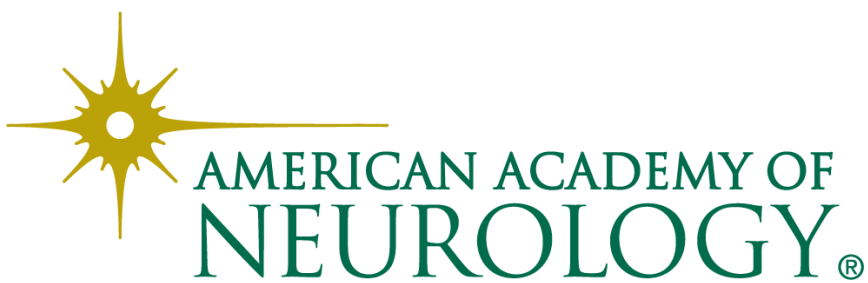

